\title{
Development of Multi-Purpose Nonwoven Filter Medium for Automobile
}

\author{
Binghui Wang (Corresponding author) \\ School of Textile, Tianjin Polytechnic University \\ $63^{\#}$ Chenglin Road, Hedong District, Tianjin 300160, China \\ Tel: 86-22-2451-4516_E-mail: kingtjpu@gmail.com
}

\begin{abstract}
With Dacron and fiber as the raw materials, the filter medium is prepared by punching and calendering the sandwich structure which is composed of the carded fiber nets reinforced with Dacron. This filter medium is used to filter oil, water and air. The experiment results indicate that this filter medium is comparable to the British and German products of the same type, and has an excellent effect on filtering impurities, water and oil. The product not only broadens the application fields of filter media, but also has a positive significance in increasing the social and economic benefits of enterprises.
\end{abstract}

Keywords: Filter medium, Punch, Process, Filtration efficiency

\section{Preface}

Filtration is a process of separating insoluble solid particles out of gases or liquids, such as gas-solid filtration and liquid-solid filtration (Tian, Caihong et al, 2006, p. 35-38). Although having already had a history of decades abroad, the development of filter medium in China is relatively late. A full range of filter media has been successfully developed since the last decade in China. However, there are few reports on the investigations of multi-purpose filter media capable of filtering oil, water and air that are applied on diesel locomotives and diesel vehicles (Qu, Cailian et al, 2006, p. 60-62). The research on multi-purpose filter media plays an important role in promoting the development of automobile manufacturing industry and prolonging the service life of locomotives.

The multi-purpose filter medium, a necessary component for oil-filtration system of diesel locomotives and vehicles, is an easily consumed product, and has a relatively short replacement cycle. At present, it has relied heavily on imports, and spent a large amount of foreign currency. For example, we import 500,000 multi-purpose filter media in all with 40 US dollars (RMB 280) for each every year, that is to say, we spend 20 million US dollars on it annually. Therefore, the research and development of multi-purpose filter media has been an urgent issue to be solved in automobile manufacturing industry, and remarkably decreased the expense of foreign currency.

This multi-purpose filter medium is prepared by punching and calendaring the sandwich structure which is composed of the carded fiber nets reinforced with Dacron. It is comparable to the foreign products of the same type.

\section{Preparation of multi-purpose filter medium for automobile}

\subsection{Selection of fiber}

The studied fiber medium is used for automotive oil filtration. Dacron fiber has advantages of high strength, low thermal deformation rate, no water absorption, excellent durability and perfect processing property (Wang, Xu et al, 2006, p. 16-18). Therefore, this fiber medium is prepared with Dacron fiber of $9 \mathrm{D} \times 75 \mathrm{~mm}$ as the main raw material, and reinforced with Dacron cloth for further improving its stability and uniformity.

\subsection{Production process}

This fiber medium is manufactured on the self-made special production lines. Its process flow diagram is shown in figure 1.

After mechanically opening, card the fiber for two times to form a fiber web, which is then punched for the first time with a six-needle array of $91 \mathrm{~mm}$ length at a punch frequency of 60 times/s, punch depth of $19 \mathrm{~mm}$, and step length of $13.33 \mathrm{~mm}$ per punching. Feed a roll of fiber web, together with $120 \mathrm{~g} / \mathrm{m}^{2}$ Dacron cloth, into the cross lapper, and punch for the second time with a six-needle array of $81 \mathrm{~mm}$ length at a punch frequency of 80 times/s, punch depth of $11 \mathrm{~mm}$, and step length of $10 \mathrm{~mm}$ per punching. Cut this fiber roll into two rolls of the same width along the middle line, then punch them for the third time with a six-needle array of $81 \mathrm{~mm}$ length at a punch frequency of 120 times/s, punch depth 
of $13 \mathrm{~mm}$, and step length of $6.66 \mathrm{~mm}$ per punching. Punch from the other side for the last time with a six-needle array of $81 \mathrm{~mm}$ length at a punch frequency of 120 times/s, punch depth of $9 \mathrm{~mm}$, and step length of $6.66 \mathrm{~mm}$ per punching. Finally, calender the obtained fiber with a calendering machine to form a multi-purpose filter medium of sandwich structure used on automotives (Wang, Xu et al, 2006, p. 16-18; Wang, Xu et al, 2006, p. 34-36).

\section{Determination of product performances}

Based on the national standard GB12218-89, the numbers of airborne particles of different diameters before and after the filter medium are respectively determined with Yog-9 airborne particle counter. The filtration efficiency is calculated with the following formula (1).

$$
\eta=\frac{C_{1}-C_{2}}{C_{1}} \times 100 \%
$$

Here, $C_{1}$ represents the number of airborne particles before filtration; $C_{2}$ represents the number of airborne particles after filtration.

Measure the static pressures before and after filtration respectively with Bosch micromanometer and tilting micromanometer, and calculate the filtration resistance with the following formula (2).

$$
\Delta P=(\text { end resistance-initial resistance }) \times k
$$

Here, $k=$ tilting ratio $\times$ density of alcohol $\times 9.8$.

Determine the filtration velocity with QDF-2A hot bulb electric anemometer, and measure the thickness of the product with YG142- II portable thickness gauge.

\section{Result and discussion}

\subsection{Analysis on the foreign products of the same type}

The client had used the foreign product. We have to develop a substitute for it. Therefore, we have investigated the data of the foreign filter medium. Table 1 exhibits the data of the sample from VDKES of Britain, and table 2 exhibits the data of the sample from MANN of Germany.

The British sample, made from wool, has a homogeneous microstructure, strong hairy appearance, small thickness deviation $( \pm 1 \mathrm{~mm}$, poor representativeness due to small area of sample) and excellent resilience. Table 1 reveals that the sample, though having a high counting efficiency, exhibits excellent hydrophilicity but poor hydrophobicity, which is because the sample is made from wool. However, the titled filter medium is made from Dacron fiber, which results in excellent hydrophobicity but poor hydrophilicity. Therefore, our product, when used in diesel engines, can effectively separate oil from water.

When the air flow rate is $500 \mathrm{~m}^{3} / \mathrm{h}$, namely, the filtration velocity is $0.39 \mathrm{~m} / \mathrm{s}$, the filtration efficiency of British sample is only $10 \%$ at particle size of $0.5 \mu \mathrm{m}$ and up to $69.9 \%$ at particle size of $1.0 \mu \mathrm{m}$, and reaches $90 \%$ at particle size of 2.0 $\mu \mathrm{m}$, then almost levels off with the further increase of particle size. For example, it is respectively $93.2 \%$ and $94.5 \%$ at particle size of $5.0 \mu \mathrm{m}$ and $10.0 \mu \mathrm{m}$.

The inner cleanliness of the German sample is less than $3 \mathrm{mg}$. Its filtration resistance increases with the experiment going on, which indicates that the collected impurity in the filter has an adverse effect on the filtration resistance. Its filtration efficiency is up to $97 \%$.

\subsection{Analysis on the self-made filter medium}

Table 3 exhibits the data of the self-made filter medium which weighs $560 \mathrm{~g} / \mathrm{m}^{2}$, and has a thickness of $3 \mathrm{~mm}$. From table 3 , we can obtain the following conclusions.

(1) Generally, the filtration efficiency of the large particles is higher than that of the small particles at the same filtration velocity. Only at the filtration velocity of $0.6 \mathrm{~m} / \mathrm{s}$ and the particle size of $5 \mu \mathrm{m}$ or $7 \mu \mathrm{m}$, as well as the filtration velocity of $1.4 \mathrm{~m} / \mathrm{s}$ and the particle size of $5 \mu \mathrm{m}$ or $7 \mu \mathrm{m}$, is the filtration efficiency of the large particles lower than that of the small particles. It is probably because the accidental factors, such as dust particles, mechanical actions, or obvious defects on the product cloth, results in the above-mentioned exceptions, in turn leads to the decline of filtration efficiency and the increase of filtration resistance.

(2) The filtration efficiency reaches $100 \%$ at the filtration velocity of $2 \mathrm{~m} / \mathrm{s}$ and particle size of $7 \mu \mathrm{m}$.

(3) The filtration resistance of the British sample is $190 \mathrm{~Pa}$, whereas that of our product is only $133.33 \mathrm{~Pa}$. Therefore, as far as the filtration resistance is concerned, our product is better than the British sample.

(4) Under the condition of $0.4 \mathrm{~m} / \mathrm{s}$ filtration velocity, the filtration efficiency reaches $73 \%$ at the particle size of $1 \mu \mathrm{m}$, higher than that of the British sample (69.9\%); whereas it is up to $86.9 \%$ and $92.0 \%$ respectively at the particle size of 2 $\mu \mathrm{m}$ and $5 \mu \mathrm{m}$, slightly lower than these of the British sample ( $90.0 \%$ and $93.2 \%$ respectively). 
We found a sample of $600 \mathrm{~g} / \mathrm{m}^{2}$ during the experiment. Table 4 exhibits the data of this type of filter medium. The above issues still exist in this sample. However, both the filtration resistance and the filtration efficiency of this sample are greater than these of the former sample. It is because the density of this sample is larger than that of the former sample, which results in not only the increase of its filtration resistance at the same filtration velocity, but also the increase of its filtration efficiency at the same particle size.

It is observed that the filtration efficiency is different at different filtration resistance. Table 5 and table 6 exhibit the filtration efficiencies at different filtration resistances.

Though having the same process parameters (weight of $560 \mathrm{~g} / \mathrm{m}^{2}$ and thickness of $3 \mathrm{~mm}$ ), different batches of product have different performances, and products obtained in different circumstances also exhibit different filtration efficiency. Therefore, it is impossible to get completely same products, only the products of similar performances can we get by regulating the manufacture process.

Punch frequency and punch density directly affect the filtration efficiency of the product. Figure 2 exhibits the correlation between punch frequency and filtration efficiency. Figure 3 exhibits the correlation between punch density and filtration efficiency.

From figure 2 and figure 3, we can see that the filtration efficiency increases with the rise of punch density which has a positive correlation with punch frequency under the given conditions, however decreases with the further rise of punch density which leads to the break of fiber. In addition, filtration efficiency increases gradually, and decreases sharply.

\subsection{Comparison between the self-made product and the foreign product}

Table 7 shows the comparison results between the self-made product and the British sample from VDKES. From table 7 , we can see that the filtration efficiency of our product is greater than that of the British sample by $0.1 \%$ at particle size of $1 \mu \mathrm{m}$, equal to that of the British sample at particle size of $2 \mu \mathrm{m}$, and greater than that of the British sample at particle size of $5 \mu \mathrm{m}$ and $10 \mu \mathrm{m}$. Meanwhile, its filtration resistance $(\leq 200 \mathrm{~Pa})$ is far less than that of the British sample. It indicates that our product is comparable to or even better than the British products of the same type.

Table 8 shows the comparison results between the self-made product and the German sample from MANN. From table 8 , we can see that our product is comparable to or even better than the German products of the same type.

The product has been applied in the oil filter system of the locomotives in China, which prolongs the service life of oil filtration system by 4 folds, and remarkably decreases the expense of foreign currency. In addition, it has also been applied in the oil filter system of the imported Steyr truck and Dawes truck, and showed an excellent filtration effect.

\section{Conclusion}

This study selects fiber as a substitute for the pure wool in the imported products to prepare the primary filter medium applied in the diesel oil filtration system of locomotives and vehicles. The product is comparable to or even better than the British and German products of the same type. The product not only broadens the application fields of filter media, but also has a positive significance in increasing the social and economic benefits of enterprises. It will be successfully applied in other fields with the further study.

\section{References}

Tian, Caihong \& Jin, Xiangyu. (2006). Functional nonwoven filter media for automobile. Technical Textiles, 5, 35-38.

Qu, Cailian \& Dou, Mingchi. (2006). Application of nonwoven filter material in automotive industry. Advanced Textile Technology, 6, 60-62.

Wang, Xu, Jiao, Xiaoning \& Zhao, Xiaocui. (2006). The air purification filter material based on needled punched nonwovens. Contamination Control \& Air-Conditioning Technology, 1, 16-18.

Wang, Xu, Jiao, Xiaoning \& Li, Jing. (2006). Application of singeing and calendering finishing on needled filter material. Technical Textile, 6, 34-36. 
Table 1. The data of the sample from VDKES of Britain

\begin{tabular}{|c|c|c|c|c|c|c|}
\hline \multirow{2}{*}{ Air flow rate $\left(\mathrm{m}^{3} / \mathrm{h}\right)$} & Resistance $(\mathrm{Pa})$ & \multicolumn{5}{|c|}{ Filtration efficiency $(\%)$} \\
\cline { 4 - 7 } & & $\geq 0.5 \mu \mathrm{m}$ & $\geq 1.0 \mu \mathrm{m}$ & $\geq 2.0 \mu \mathrm{m}$ & $\geq 5.0 \mu \mathrm{m}$ & $\geq 10.0 \mu \mathrm{m}$ \\
\hline 500 & 190 & 10.0 & 69.9 & 90.0 & 93.2 & 94.5 \\
\hline 1000 & 230 & & & & & \\
\hline
\end{tabular}

Table 2. The data of the sample from MANN of Germany

\begin{tabular}{|c|c|c|c|c|c|}
\hline \multirow{2}{*}{$\begin{array}{c}\text { Rated flow rate } \\
(\mathrm{L} / \mathrm{h})\end{array}$} & $\begin{array}{c}\text { Inner cleanliness } \\
(\mathrm{mg})\end{array}$ & \multicolumn{2}{|c|}{ Resistance $(\mathrm{Pa})$} & Filtration efficiency & $\begin{array}{c}\text { Experiment period } \\
(\%)\end{array}$ \\
\cline { 3 - 5 } & & Initial resistance & End resistance & & \\
\hline 120 & $\leq 3$ & 60 & 230 & 97 & 39 \\
\hline
\end{tabular}

- Rated flow rate: air volume passed through in a certain period.

- Inner cleanliness: the amount of residual impurities in the air filter before filtration.

- Filtration efficiency: the mass ratio of the dust particles collected on the filter to the dust particles entering the filter at a fixed air flow rate in an air filter equipped with a filter core.

Table 3. The data of the self-made $720^{\#}$ filter medium of $560 \mathrm{~g} / \mathrm{m}^{2}$

\begin{tabular}{|c|c|c|c|c|c|c|c|}
\hline \multirow{2}{*}{ Filtration velocity $(\mathrm{m} / \mathrm{s})$} & \multirow{3}{*}{ Resistance $(\mathrm{Pa})$} & \multicolumn{5}{|c|}{ Grouped counting efficiency $(\%)$} \\
\cline { 3 - 9 } & & $0.5 \mu \mathrm{m}$ & $0.7 \mu \mathrm{m}$ & $1 \mu \mathrm{m}$ & $2 \mu \mathrm{m}$ & $5 \mu \mathrm{m}$ & $7 \mu \mathrm{m}$ \\
\hline 0.2 & 54.9 & 4.3 & 37.1 & 53.0 & 71.0 & 84.0 & 86.1 \\
\hline 0.4 & 133.3 & 23.1 & 59.9 & 73.0 & 86.9 & 92.0 & 92.7 \\
\hline 0.6 & 199.9 & 18.7 & 67.9 & 81.0 & 89.0 & 91.9 & 87.5 \\
\hline 0.8 & 270.9 & 29.2 & 77.2 & 86.0 & 93.2 & 94.1 & 97.4 \\
\hline 1.0 & 327.3 & 39.4 & 82.8 & 90.8 & 95.5 & 98.0 & 99.0 \\
\hline 1.2 & 384.2 & 43.4 & 86.6 & 92.1 & 96.1 & 96.0 & 97.2 \\
\hline 1.4 & 435.1 & 43.7 & 87.6 & 93.9 & 97.6 & 98.9 & 96.1 \\
\hline 1.6 & 527.5 & 46.6 & 91.6 & 95.6 & 97.8 & 95.7 & 96.3 \\
\hline 1.75 & 555.7 & 60.0 & 94.0 & 96.2 & 98.6 & 96.3 & 96.2 \\
\hline 2.0 & 615.9 & 62.5 & 95.3 & 97.4 & 98.0 & 98.6 & 100 \\
\hline
\end{tabular}

- The filter medium weighs $560 \mathrm{~g} / \mathrm{m}^{2}$, and has a thickness of $3 \mathrm{~mm}$. 
Table 4. The data of the self-made $720^{\#}$ filter medium of $600 \mathrm{~g} / \mathrm{m}^{2}$

\begin{tabular}{|c|c|c|c|c|c|c|c|}
\hline \multirow{2}{*}{ Filtration velocity (m/s) } & \multirow{2}{*}{ Resistance $(\mathrm{Pa})$} & \multicolumn{5}{|c|}{ Grouped counting efficiency $(\%)$} \\
\cline { 3 - 8 } & & $0.5 \mu \mathrm{m}$ & $0.7 \mu \mathrm{m}$ & $1 \mu \mathrm{m}$ & $2 \mu \mathrm{m}$ & $5 \mu \mathrm{m}$ & $7 \mu \mathrm{m}$ \\
\hline 0.2 & 62 & 4.9 & 39.0 & 55.0 & 78.0 & 84.5 & 86.9 \\
\hline 0.4 & 145 & 26.0 & 62.0 & 75.0 & 88.0 & 93.0 & 93.0 \\
\hline 0.6 & 206.8 & 27.0 & 69.0 & 82.0 & 90.0 & 93.6 & 94.0 \\
\hline 0.8 & 289 & 29.9 & 78.2 & 86.8 & 93.0 & 95.0 & 96.0 \\
\hline 1.0 & 335.4 & 39.9 & 84 & 90.9 & 98 & 98 & 98 \\
\hline 1.2 & 399 & 45.0 & 90.0 & 93.0 & 98.2 & 98.0 & 98.8 \\
\hline 1.4 & 456.3 & 47.0 & 91.0 & 95.9 & 98.3 & 98.9 & 99.2 \\
\hline 1.6 & 562 & 48.8 & 92.5 & 96.6 & 98.5 & 98.9 & 99.3 \\
\hline 1.75 & 594 & 62.0 & 97.0 & 97.8 & 99.0 & 99.0 & 99.5 \\
\hline 2.0 & 635.9 & 65.0 & 99.4 & 99.0 & 99.2 & 99.0 & 99.8 \\
\hline
\end{tabular}

- The filter medium weighs $600 \mathrm{~g} / \mathrm{m}^{2}$, and has a thickness of $3 \mathrm{~mm}$.

Table 5. The data of the self-made $720^{\#}$ filter medium at low filtration resistance

\begin{tabular}{|c|c|c|c|c|c|c|}
\hline \multirow{2}{*}{ Filtration velocity $(\mathrm{m} / \mathrm{s})$} & \multirow{2}{*}{ Resistance $(\mathrm{Pa})$} & \multicolumn{5}{|c|}{ Grouped counting efficiency (\%) } \\
\cline { 3 - 7 } & & $0.7 \mu \mathrm{m}$ & $1.0 \mu \mathrm{m}$ & $2.0 \mu \mathrm{m}$ & $5.0 \mu \mathrm{m}$ & $7.0 \mu \mathrm{m}$ \\
\hline 0.4 & 68 & 49.9 & 66.0 & 79.2 & 80.1 & 88.0 \\
\hline 0.8 & 111 & 55.9 & 69.0 & 90.0 & 94.6 & 96.2 \\
\hline 1.2 & 154 & 59.0 & 71.0 & 90.9 & 95.3 & 96.5 \\
\hline 1.55 & 178 & 60.0 & 73.6 & 94.2 & 96.7 & 97.3 \\
\hline 1.73 & 195 & 64.9 & 75.0 & 95.9 & 98.3 & 98.6 \\
\hline 1.95 & 269 & 73.5 & 78.0 & 95.9 & 98.9 & 90.0 \\
\hline
\end{tabular}

- The filter medium weighs $560 \mathrm{~g} / \mathrm{m}^{2}$, and has a thickness of $3 \mathrm{~mm}$.

Table 6 . The data of the self-made $720^{\#}$ filter medium at high filtration resistance

\begin{tabular}{|c|c|c|c|c|c|c|}
\hline \multirow{2}{*}{ Filtration velocity $(\mathrm{m} / \mathrm{s})$} & \multirow{2}{*}{ Resistance $(\mathrm{Pa})$} & \multicolumn{5}{|c|}{ Grouped counting efficiency (\%) } \\
\cline { 3 - 7 } & & $0.7 \mu \mathrm{m}$ & $1.0 \mu \mathrm{m}$ & $2.0 \mu \mathrm{m}$ & $5.0 \mu \mathrm{m}$ & $7.0 \mu \mathrm{m}$ \\
\hline 0.4 & 129.3 & 76.4 & 83.1 & 88.7 & 94.5 & 92.9 \\
\hline 0.8 & 286 & 91.0 & 93.7 & 96.5 & 96.5 & 95.1 \\
\hline 1.0 & 344 & 92.2 & 94.4 & 96.8 & 97.2 & 98.2 \\
\hline 1.2 & 392 & 94.1 & 93.7 & 96.3 & 95.7 & 97.9 \\
\hline 1.55 & 468 & 94.5 & 93.8 & 91.1 & 94.0 & 92.2 \\
\hline
\end{tabular}

- The filter medium weighs $560 \mathrm{~g} / \mathrm{m}^{2}$, and has a thickness of $3 \mathrm{~mm}$. 
Table 7. The comparison results between the self-made product and the British sample

\begin{tabular}{|c|c|c|c|c|c|c|}
\hline \multirow{2}{*}{ Type of product } & Filtration velocity $(\mathrm{m} / \mathrm{s})$ & \multirow{3}{*}{ Resistance $(\mathrm{Pa})$} & \multicolumn{4}{|c|}{ Grouped counting efficiency (\%) } \\
\cline { 4 - 7 } & & & $\geq 1 \mu \mathrm{m}$ & $\geq 2 \mu \mathrm{m}$ & $\geq 5 \mu \mathrm{m}$ & $\geq 10 \mu \mathrm{m}$ \\
\hline Self-made product & 1.7 & $\leq 200$ & 70 & 90 & 95 & 95 \\
\hline British sample & 1.7 & 230 & 69.9 & 90 & 93.2 & 94.5 \\
\hline
\end{tabular}

Table 8. The comparison results between the self-made product and the German sample

\begin{tabular}{|c|c|c|c|c|c|c|}
\hline Type of product & $\begin{array}{c}\text { Rated total } \\
\text { flow rate }(\mathrm{L} / \mathrm{h})\end{array}$ & $\begin{array}{l}\text { Inner cleanliness } \\
\qquad(\mathrm{mg})\end{array}$ & $\begin{array}{l}\text { Initial resistance } \\
\qquad(\mathrm{kPa})\end{array}$ & $\begin{array}{l}\text { Experiment } \\
\text { period }(\mathrm{min})\end{array}$ & $\begin{array}{l}\text { Separation } \\
\text { ability (\%) }\end{array}$ & $\begin{array}{l}\text { Initial filtration } \\
\text { efficiency }(\%)\end{array}$ \\
\hline $\begin{array}{c}\text { Self-made } \\
\text { product }\end{array}$ & 120 & 1.9 & 6 & 40 & 90 & 97.7 \\
\hline $\begin{array}{c}\text { German sample } \\
\text { from MANN }\end{array}$ & 120 & $<3$ & 6 & 39 & $\geq 90$ & 97 \\
\hline
\end{tabular}

- Both products are applied on diesel vehicles and compared.

- Type of the fine filter on diesel vehicle: AZ15089295; type of the primary filter core: 614080740 .

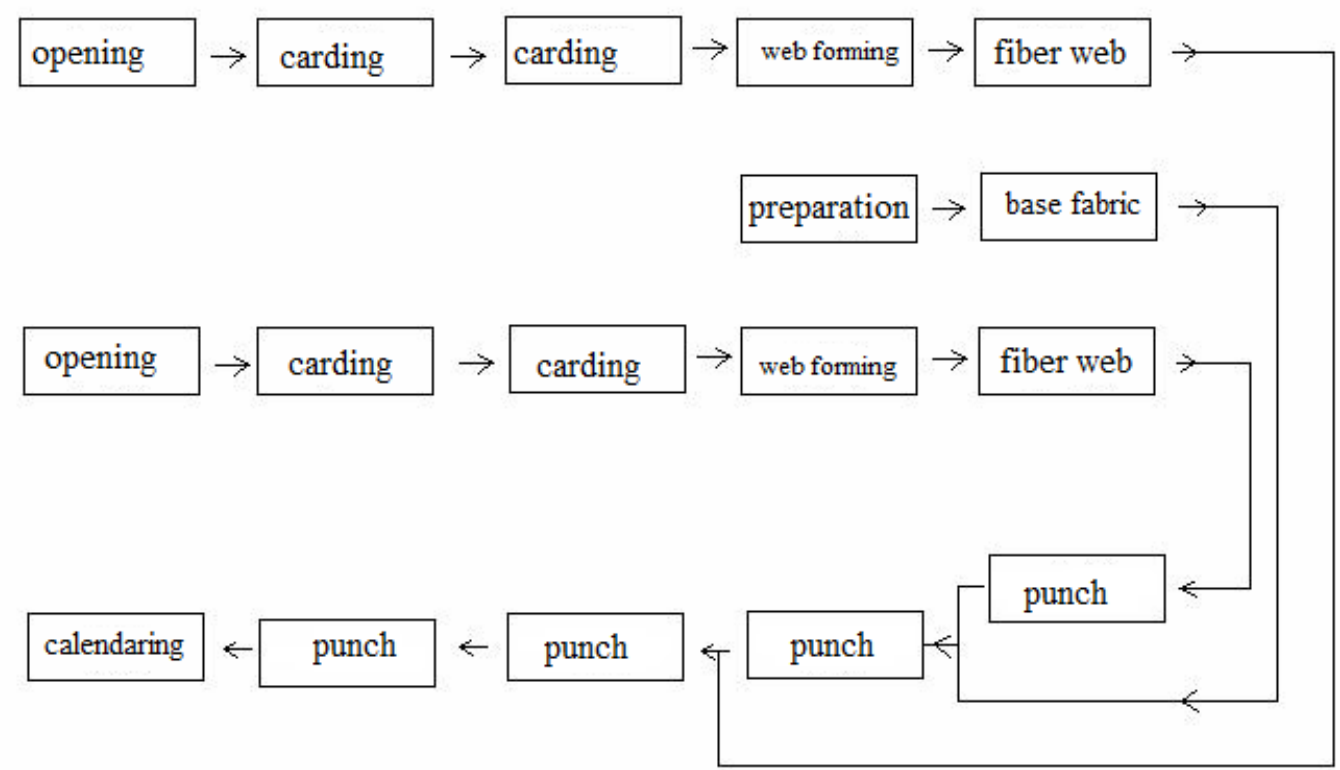

Figure 1. The process flow diagram of filter medium 


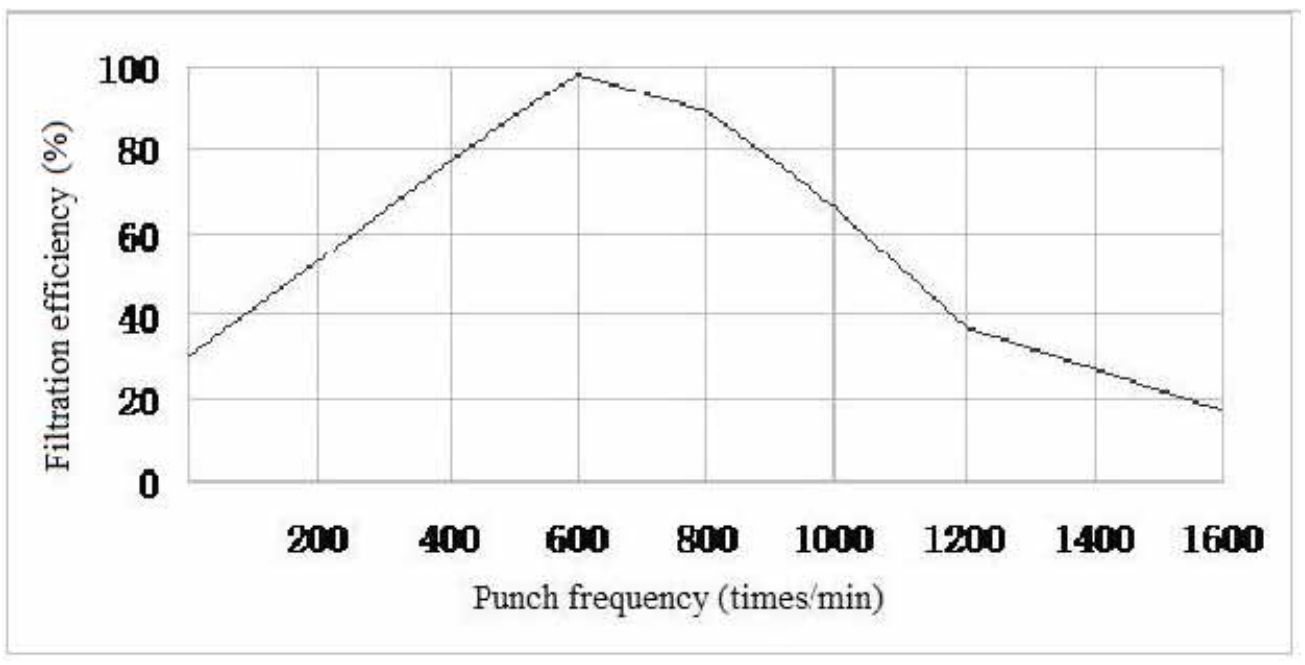

Figure 2. The correlation between punch frequency and filtration efficiency

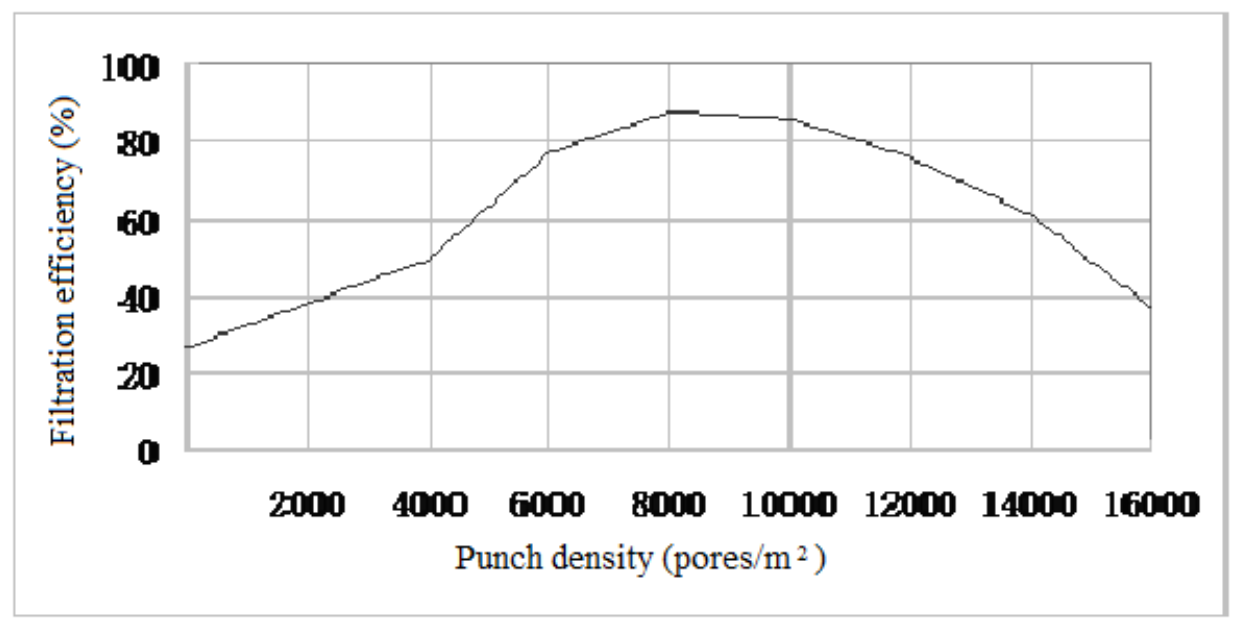

Figure 3. The correlation between punch density and filtration efficiency 